\title{
Advancement of Fixed Net Broadband connection in Copper and Hybrid Fiber with VDSL and GIGA COAX
}

\author{
Ayan Chatterjee \\ Department of IT, Jadavpur \\ University \\ Kolkata, India
}

\author{
Uttam Kumar Roy, PhD \\ Department of IT, Jadavpur \\ University \\ Kolkata, India
}

\author{
Nibedita Pahari \\ Computer Sc. \& Engineering, \\ WBUT \\ Kolkata, India
}

\begin{abstract}
Telecom industry can be classified in two main streams like fixed line service and wireless cellular service. Along with internet BB services other services like IPTV, cable TV, VoIP, and VAS services are also provided by different telecommunication companies. The industry has to play a vital role in this age of information.

The demands are increasing, more consumers are getting attached to this sector, and other industrial \& educational sectors are incomplete without any communication that can be either data or voice or both. Keeping in mind the growing demands of fast speed, delivery of voice and data, telecommunication industries are doing a revolution in human communication. Different new technologies are getting deployed to bring more consumers, filling rural-urban gap in Tele density, attracting consumers with more speeds and different Value added services.
\end{abstract}

\section{Keywords}

ETOM; DSL; ISP; Modem; Attenuation; Cabinet; DOCSIS; Frequency; Microwave; Router; GSM; VLAN; Head End; OLT; ONT; ODF; eBSA etc.

\section{INTRODUCTION}

The history of telecommunication is quite important in the field of communication engineering. In 1870, two inventors Elisa Gray \& Graham Bell competed to make first telephone and Graham Bell patented it first and is now regarded as inventor of telephone. In 1876, first talking started with electricity and next year, voice transmission started over lines and in 1896, first rotary dial was born by US associate Almon Brown Strowger and now it is replaced by tap button. In 1915, first telephone call was established across the continent in between G.Bell (NY) and Watson (San Francisco) and in 1926 it crossed the country border. In 1919, AT \& T Inc. the American Multinational telecom corporation created the dimension of first telephone receiver. In 1946, national numbering plan concept was introduced and in 1973, first mobile phone was created by Martin Cooper while working for Motorola. In 1979, the first Hamburger phone came in the market which was looking like a burger. In 1983, Motorola Dynatac $8000 \mathrm{X}$ came into market with $1.5 \mathrm{hrs}$ talk time and 8 hours of standby. In 1990, first Orange and One2One phone came to market in UK and mobile prices fall and became more accessible to everyone. In 1991, $2 \mathrm{G}$ mobile technology was deployed in Finland, in 2001, first 3G was deployed in Japan and in 2012, first $4 \mathrm{G}$ service launched in UK. The first iPhone came in 2007 by Apple.
The telecommunication industry is rapidly growing. First it had a target to deliver only voice and later the demand of data came. So, a lot of technological modifications happened in voice (circuit switching, message switching, and packet switching) and data $\&$ different types of devices are created to support those changes. Now, data-TV-voice all are merged on single cable service. Besides, we are using different wireless services where fixed line connections are either not possible or costly. Day by day, consumers are increasing with their demand of fast internet so new technologies are deployed to meet the target.

\section{FIXED LINE SERVICE}

\subsection{Network Layers}

Internet communication does maintain a standard communication model like ISO-OSI as stated below:

\begin{tabular}{|c|}
\hline $\begin{array}{c}\text { Application } \\
\text { Provides access to the OSI environment for users }\end{array}$ \\
Presentation \\
Provides Independence from data representation \\
\hline $\begin{array}{c}\text { Session } \\
\text { Establish, manage, terminate connection }\end{array}$ \\
$\begin{array}{c}\text { Transport } \\
\text { Connection oriented service }\end{array}$ \\
Routing, congestion control, connection oriented or \\
connectionless
\end{tabular}

Fig 1: Network Layers

\subsection{Devices \& Protocols}

Different network devices and protocols are stated as below corresponding to respective ISO-OSI network layer: 
Table 1: Devices \& Protocols

\begin{tabular}{|c|c|c|}
\hline Layer & Device & Protocol \\
\hline Physical & $\begin{array}{l}\text { Cabling system } \\
\text { components, Hub, } \\
\text { repeater, Network } \\
\text { Interface Card (NIC), } \\
\text { Adapters that connect } \\
\text { media to physical } \\
\text { interfaces, Connector } \\
\text { design and pin } \\
\text { assignments }\end{array}$ & $\begin{array}{l}\text { Ethernet, } \\
\text { Bluetooth, } \\
\text { IEEE802.11 }\end{array}$ \\
\hline Data Link & $\begin{array}{l}\text { Bridges, Ethernet and } \\
\text { Token Ring switches. }\end{array}$ & ATM,PPP,HDLC \\
\hline Network & Router & IP,ARP,ICMP \\
\hline Transport & $\begin{array}{l}\text { Gateways, Proxy } \\
\text { Servers, Application } \\
\text { Switches, Content } \\
\text { Filtering Firewalls }\end{array}$ & TCP,UDP \\
\hline Session & $\begin{array}{l}\text { Gateways, Proxy } \\
\text { Servers, Application } \\
\text { Switches, Content } \\
\text { Filtering Firewalls }\end{array}$ & RTP, SIP \\
\hline Presentation & $\begin{array}{l}\text { Gateways, Proxy } \\
\text { Servers, Application } \\
\text { Switches, Content } \\
\text { Filtering Firewalls }\end{array}$ & SSL \\
\hline Application & $\begin{array}{l}\text { Gateways, Proxy } \\
\text { Servers, Application } \\
\text { Switches, Content } \\
\text { Filtering Firewalls }\end{array}$ & $\begin{array}{c}\text { HTTP,FTP.SMTP, } \\
\text { SNMP,RPC,DNS, } \\
\text { DHCP }\end{array}$ \\
\hline
\end{tabular}

\subsection{Different types of Cables}

Different types of cables used in fixed line BB services to home/office and their advantages and disadvantages are described as below:

\section{Table 2: Cables}

\begin{tabular}{|l|l|}
\hline Type & \multicolumn{1}{|c|}{ Description } \\
\hline Pair & $\begin{array}{l}\text { Pair of insulated copper wires. It is used in the } \\
\text { field of telecommunication for long time. } \\
\text { Twisting pair of cables help in reducing } \\
\text { crosstalk and noise. Its bandwidth support is } \\
\text { limited and it is attenuation prone. There are } \\
\text { two types of cables - UTP or unshielded and }\end{array}$ \\
$\begin{array}{l}\text { STP or shielded. In the former two insulated } \\
\text { cables are twisted together and it is normally } \\
\text { used in normal data communication \& } \\
\text { telephones. Later holds another shield on the } \\
\text { twist that helps to prevent outside crosstalk or } \\
\text { noise (inductive and capacitive coupling) and } \\
\text { it is used in between racks, equipments and } \\
\text { buildings. }\end{array}$ \\
\hline Coaxial & $\begin{array}{l}\text { It has a single solid copper core inside of a } \\
\text { cladding and it is able to carry more frequency } \\
\text { (80 times more than TP cable). It is well } \\
\text { enough to carry data as well as television }\end{array}$ \\
\hline
\end{tabular}

\begin{tabular}{|l|l|}
\hline signals. It is also applicable for achieving \\
gigabits speed with fiber (OLT \& GPON \\
optical splitter) \& DOCSIS 3.1 amplifier at \\
customer end. It is very much cost effective for \\
short range transmission for residential \\
purpose. It has anti-jamming capability and it \\
can transmit data in stable manner without \\
interference affect. It is also useful in digital \\
audio, radio transmitter and receiver. Example: \\
YOUSEE system of Denmark uses COAX line \\
at last end of home connection. \\
\hline Fiber Optic & $\begin{array}{l}\text { It carries data 26000 times faster than TP } \\
\text { cable. It carries data in the form of pulses of } \\
\text { light so it is very fast. It is made of glass with } \\
\text { plastic coating. It uses the concept of total } \\
\text { internal reflection to transmit pulses at the } \\
\text { speed of light. Using this cable we can achieve } \\
\text { gigabit speed easily. It can carry pulses either } \\
\text { in single mode (only one pulse and for long } \\
\text { distance) or Multimode (more than one pulse } \\
\text { and for short range) It is not probe to } \\
\text { attenuation so P2P fiber connection can be } \\
\text { given up to over 2 KM. It is reliable and } \\
\text { noise/crosstalk resistant but costly. It can be } \\
\text { used as backbone of network system to } \\
\text { achieve high speed at customer end. }\end{array}$ \\
\hline
\end{tabular}
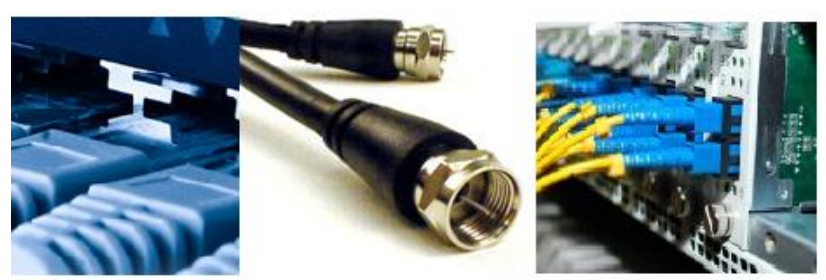

Fig 2: Cables (TP, Coax, FO)

\subsection{Connection to customer house}

Below are the steps to provide a BB connection to a customer for a company XYZ where main network setup of the company is at city $\mathrm{C} 1$ and customer is at another city $\mathrm{C} 2$. Here we have considered, customer will be given TV services along with BB plan (but it might happen, customer can take TV feature only or BB feature only over the cable that has been taken from corporate office to customer home/office). Below steps are required to offer basic service to any customer:

- Install powerful Routers (Ex. Juniper) to form the core Network at $\mathrm{C} 1$ that will connect to rest of the world or outside Internet traffic flow will be pumped here.

- Bring connections to $\mathrm{C} 1$ Central Office via another Router $\rightarrow$ A

- Bring connection from A to another city's (C2) Main station via another Router $\rightarrow$ B

- We can geographically divide C2 to 4 areas and each of them represents $\mathrm{CO}$ or Central Office.

- From B, 4 CO are connected via Routers and COs are interconnected by mesh topology and it creates L2 Ring. 
- Multiplexing switching devices (Example: DSLAM) are present at CO and they are terminated at L2 \& routers are present at L3.

- If multiplexing devices are DSLAMs then cards are installed at designated rack \& slot.

- Cards have multiple ports based on category (ADSL, ADSL2+, VDSL, SHDSL, Fiber, and GPON) and from there lines are taken out to customer premise (CPE).

- VLANs are created in L2 which are terminated at L3. L2 defines particular no of VLANs based on capacity planning. VLAN's span is from UNI (customer side) to NNI (PE Router side). Inner VLAN takes place inside a VLAN and outer VLAN happens at router termination where multiple VLAN terminates.

Example: If two customers are there one wants $10 \mathrm{Mbps} \&$ another wants 50Mbps BB speed. From Same DSLAM they are given connection. Then how they are assigned two different speeds?

Answer: First pre-line qualification happens. Two VLANs must be there one will support lines for $50 \mathrm{Mbps} \&$ another will support 10Mbps. First it will be tried if in one VLAN customer can be offered with required speed by capacity planning if yes then fine else customer is given connection to other VLAN.

\section{VLAN1: 50Mbps VLAN2: 10Mbps}

\section{How TV connection is given:}

TV Signal capturing at head end $\rightarrow$ Core Network $\rightarrow$ L3 $\rightarrow$ L2 Ring (VLAN allocation) $\rightarrow$ DSLAM/Port $\rightarrow$ connection to Customer (CPE)

Example: Different customer requirement \& different VLAN:

VLAN1: 10 Mbps BB speed. VLAN2: 50 Mbps BB Speed.

VLAN3: TV VLAN4: TV + 10 Mbps VLAN5: TV + 50 Mbps

The above setup is used in Denmark and for TDC ISP users.

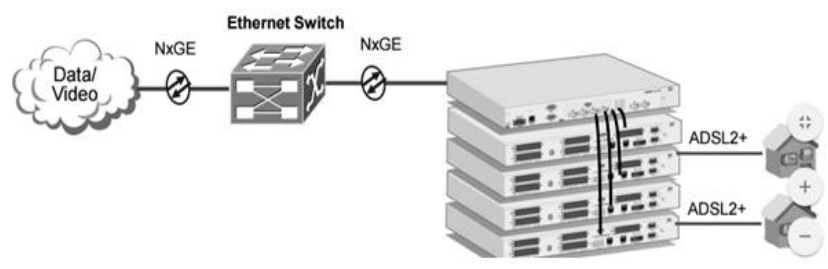

Fig 3: DSLAM based connection

The above connection setup can be given to particular customer or office based on copper or fiber lines that have been taken out from DSLAMs (Example: Siemens, Ericsson, and Alcatel). On DSLAM side multiple types of cards are installed and cards has specific no of ports from where connection is taken out to customer premise. Example: VDSL/ADSL2+ card have 48 ports and GPON has 8 ports.

Siemens: It supports SHDSL service. (SHDSL card is installed). It is costly. It was introduced to give fast connection to rural areas (12KM).
Ericsson: It supports ADSL service. (ADSL card is installed that TDC has today. It can also support VDSL card)

Alcatel: It can support multiple cards like ADSL, ADSL 2+, VDSL, Fiber, GPON etc. Today, Alcatel Lucent DSLAM is used worldwide.

In TDC system, another type of DSLAM is used namely Hybrid DSLAM. It has 8 ports. 4 supports line and another 4 are splitters that split line $\&$ telephone.

\section{Copper Connection:}

DSLAM Port (holds VLAN ID) $\rightarrow$ Cross-Box (Jack) $\rightarrow$ Terminal Box (Jack) $\rightarrow$ WFM team $\rightarrow$ Connects to Home (CPE)

From Cross Box, multiple TBs are connected. Copper connections are like P2P. In the figure\#4, the $3^{\text {rd }}$ connection is of this type. Copper line uses twisted pair cable. The copper connection can have fiber backbone to give better speed to customers.

\section{Fiber Connection:}

- $\quad$ P2P (Fast Ethernet \& Gigabit Ethernet) NELT-B card. In the figure\#4, the $4^{\text {th }}$ connection is of this type.

- $\quad$ GPON (from DSLAM (ODF), OLT side connection is taken and a cable is ended at optical splitter. The splitter contains the customer port. From Splitter multiple connections are taken out at ONT/ Customer side. It can support max. 128 customers as GPON card have 8 ports. Corresponding supporting card is NGLT-C.

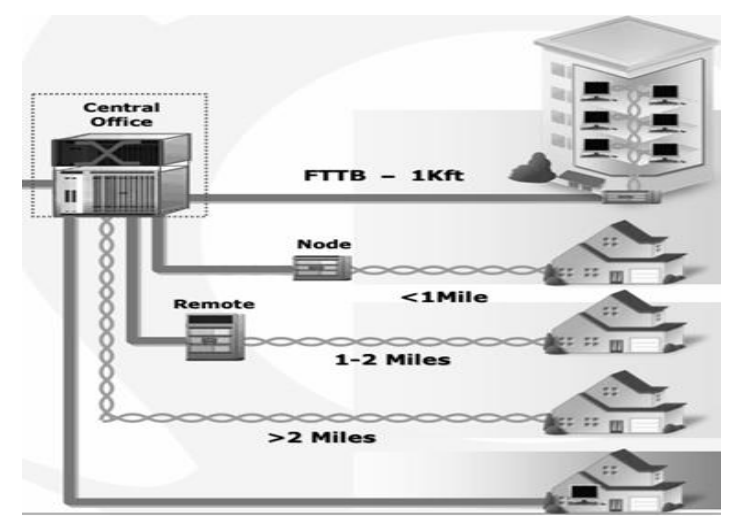

Fig 4: Home connection

\section{Coax Based Connection:}

Head End $\rightarrow<$ fiber $>$ CO (CMTS/OLT) $\rightarrow<$ <iber $>$ Optical Node $\rightarrow<$ Coax $>$ Cabinet $\rightarrow<$ Amplifier $>$ Customer wall plug $\rightarrow \mathrm{CPE}$

It is largely used in Denmark's Yousee Network. It is hybrid. No DSLAM is used in the Yousee Network.

All copper, fiber \& coax connection do maintain separate inventory systems that can be physical or virtual. 


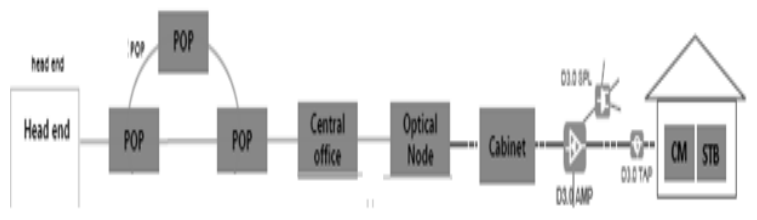

Fig 5: Coax connection

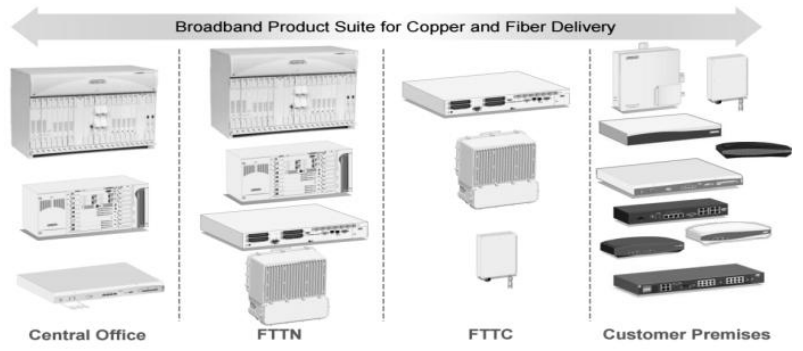

Fig 6.a: Telecom Equipments

\section{MPLS VPN Network (CISCO):}

It is set up by ISP only once and new customers are added here as per the requirement when needed.

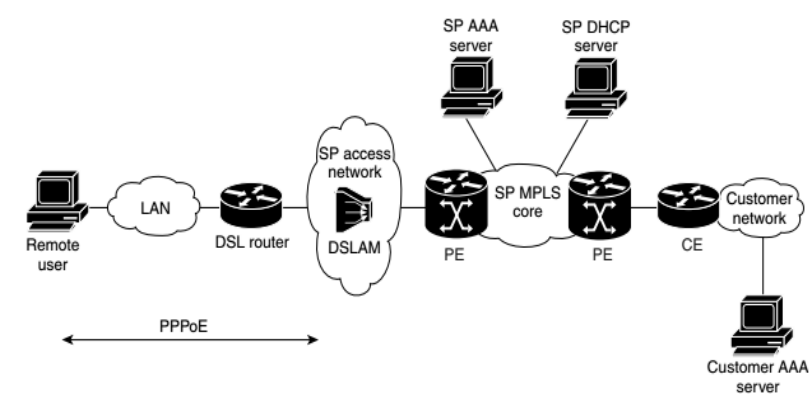

Fig 6.b: MPLS VPN NW

Table 5: MPLS VPN Components

\begin{tabular}{|l|l|}
\hline $\begin{array}{l}\text { Customer } \\
\text { Edge router }\end{array}$ & $\begin{array}{l}\text { Its function is to create a session to a SP's } \\
\text { PE router. }\end{array}$ \\
\hline $\begin{array}{l}\text { Provider } \\
\text { Edge router }\end{array}$ & $\begin{array}{l}\text { It is located at the edge of SP MPLS Core } \\
\text { NW. It creates session with one or more CE } \\
\text { routers and passes the traffic to the VPNs } \\
\text { associated with those CE. But it has no } \\
\text { knowledge of routes to VPNs those CEs are } \\
\text { not connected to it. }\end{array}$ \\
\hline $\begin{array}{l}\text { Provider } \\
\text { router (P) }\end{array}$ & $\begin{array}{l}\text { They don't have any CE or VPN } \\
\text { information. They do label switching. }\end{array}$ \\
\hline
\end{tabular}

\subsection{Connection across the Countries}

Below flow shows how communication happens in between two countries like Denmark/UK \& India.

A-End (Denmark/UK) $\rightarrow$ TDC/Yousee/BT POP $\rightarrow$ Undersea Cable owned by VSNL/ATNT (T3 fiber optic line lease $\rightarrow$ $45 \mathrm{Mbps}) \rightarrow$ India BSNL POP $\rightarrow$ Router $\rightarrow$ Office/Home or $\mathbf{Z}$ End

\section{EVOLUTION OF SERVICES}

Different types of fixed line connections are described as below:

- $\quad$ Narrow Band (Dial UP \& ISDN)

- $\quad$ Fixed line BB (DSL, FTTC, FTTH, Power Line)

- WPA or Fixed Wireless Access

Narrow Band (Dial-up \& ISDN)

\begin{tabular}{|c|c|c|}
\hline Type & Description & Speed \\
\hline Dial Up & $\begin{array}{l}\text { Very old form of internet access. } \\
\text { Internal modem needs to install on } \\
\text { CPU slot and direct copper telephone } \\
\text { wire (POTS) is jacked to the modem } \\
\text { to get internet access. So, at the same } \\
\text { time Voice and Data service are not } \\
\text { possible and charge is made similar to } \\
\text { phone call. It is very slow, unreliable } \\
\text { and no separate subscription is } \\
\text { required from ISP. It is dead now. }\end{array}$ & $\begin{array}{c}56 \mathrm{Kbps} \\
\text { upload } \\
\text { and } 48 \\
\text { kbps with } \\
\text { V.92 } \\
\text { standard. }\end{array}$ \\
\hline ISDN & $\begin{array}{l}\text { Full service is in digital signal so no } \\
\text { modem is required. It is } \\
\text { comparatively reliable but with high } \\
\text { latency. It is expensive as compared } \\
\text { to BB service. It is good for specific } \\
\text { services like VoIP. It is phased out. } \\
\text { Example: BT's ISDN products (Home } \\
\text { Highway, Midband). }\end{array}$ & $\begin{array}{l}\text { 64Kbps } \\
\text { but it can } \\
\text { be } \\
\text { increased } \\
\text { to } \\
\text { 128Kbps } \\
\text { with } \\
\text { bonding } \\
\text { channel. }\end{array}$ \\
\hline
\end{tabular}

Fixed Line (SDSL, ADSL, ADSL2+, VDSL, SHDSL)

\begin{tabular}{|c|c|c|}
\hline Type & Description & Speed \\
\hline SDSL & $\begin{array}{c}\text { Both upstream and downstream } \\
\text { has similar speed. It is much } \\
\text { similar to HDSL with single TP } \\
\text { cable. }\end{array}$ & $\begin{array}{c}\text { 1.544 Mbps } \\
\text { (US- } \\
\text { Canada) \& } \\
\text { 2.048 Mbps } \\
\text { (EU) in each } \\
\text { direction of } \\
\text { a duplex } \\
\text { line. }\end{array}$ \\
\hline ADSL & $\begin{array}{l}\text { Splitter \& modem is setup at } \\
\text { customer premise. TP copper } \\
\text { telephone line is connected to one } \\
\text { end of the splitter and it splits low } \\
\text { frequency voice and high } \\
\text { frequency data and sends to } \\
\text { telephone and modem } \\
\text { respectively. Modem converts the } \\
\text { analog to digital conversion or } \\
\text { vise-versa. It offers better speed. } \\
\text { Now, both phone call and internet } \\
\text { access is possible. It is cheap, fast } \\
\text { and easy to install. Each } \\
\text { connection is fixed to a phone } \\
\text { connection. It is prone to ISP } \\
\text { congestion \& attenuation (More } \\
\text { than } 6.5 \mathrm{KM} \rightarrow \text { performance } \\
\text { degrades) }\end{array}$ & $\begin{array}{c}\text { 8Mbps } \\
\text { download } \\
\text { with } 448- \\
832 \mathrm{Kbps} \\
\text { upload } \\
\text { speed. }\end{array}$ \\
\hline ADSL2 & Best effort service similar to & $24 \mathrm{Mbps}$ \\
\hline
\end{tabular}




\begin{tabular}{|c|c|c|}
\hline+ & $\begin{array}{c}\text { ADSL. With Port bonding it can } \\
\text { offer much better speed and it can } \\
\text { cover better distance than ADSL. } \\
\text { Both ADSL \& ADSL2+'s BW can } \\
\text { be shared among end customers. }\end{array}$ & $\begin{array}{c}\text { down \& 1.4 } \\
\text { Mbps up. }\end{array}$ \\
\hline VDSL/ & $\begin{array}{c}\text { They are very much useful in } \\
\text { copper based short range speedy } \\
\text { connection in Hybrid-Fiber } \\
\text { network (in last mile). VDSL is } \\
\text { used where high BW is required } \\
\text { like VoIP telephony, HDTV } \\
\text { transmission etc. VDSL is costly. } \\
\text { It is used mainly in Korea and } \\
\text { Japan. It is Very-high-bit-rate } \\
\text { digital subscriber line. ADSL is } \\
\text { still better for home connection. }\end{array}$ & $\begin{array}{c}\text { Upload } \\
\text { and 16Mbps } \\
\text { Upload }\end{array}$ \\
\hline SHDSL & $\begin{array}{c}\text { This service is provided from } \\
\text { Local Exchange to a place - rural } \\
\text { areas where normal DSL lines fail. } \\
\text { It can be extended to 12 KM and } \\
\text { better speed can be obtained with } \\
\text { two phone lines or twisted pair. }\end{array}$ & \\
\hline
\end{tabular}

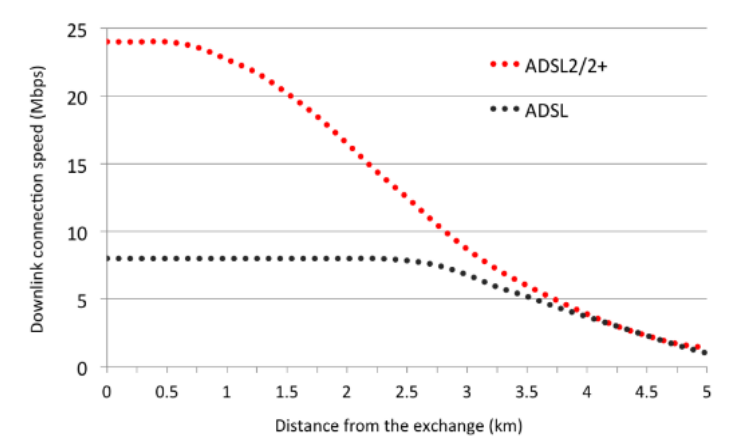

Fig: 7. ADSL VS ADSL2+

\section{Hybrid (FTTC, FTTB) \& Full Fiber (FTTH)}

Cable with hybrid fiber optic fiber BB technologies are jointly called as FTTN or Fiber to the network. Its purpose use to use copper/coax cable only at last mile and other connections to replace with FO cable to enhance speed at customer home/offices. VDSL is generally used in last mile in FTTN. Its installation \& maintenance is costly.

- FTTB: It is fiber to the building. From Exchange office/distribution point to building endpoint, copper wire is replaced with FO cable and from building endpoint to different apartments connection is given on copper. It can provide 50-100 Mbps speed.

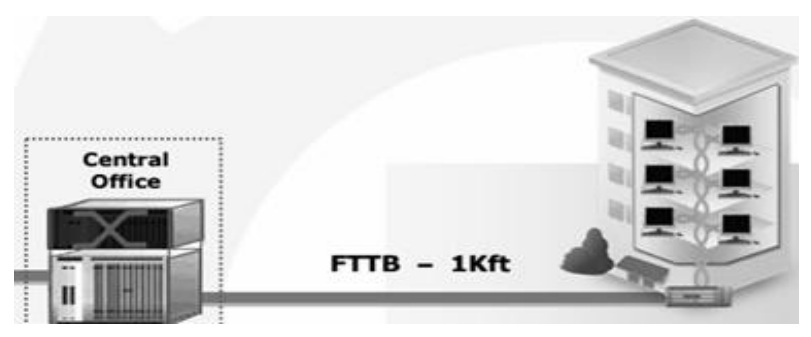

Fig: 8 FTTB
- $\quad$ FTTC: It is fiber to the cabinet. In this case, fiber optic cable runs from Exchange office/distribution point to roadside cabinet and from there either copper/coax (existing) runs to customer premise. It can provide download speeds $40 \mathrm{Mbps} / 80 \mathrm{Mbps}$ with upload speed 2Mbps/20Mbps.
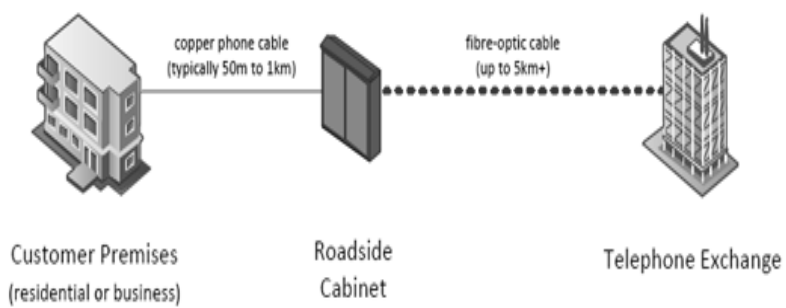

Fig: 9 FTTC

- $\quad$ FTTH: It is fiber to the home. In this case, fiber optic cable runs from Exchange office/distribution point to customer premise to provide huge speed like $330 \mathrm{Mbps}$ (down) with $30 \mathrm{Mbps}$ (upload). It is full fiber connection so it able to cover more distance than FTTC \& FTTB.

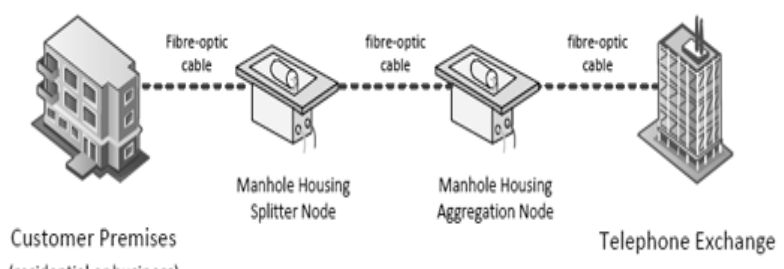

Fig: 10 FTTH

- $\quad$ Fixed Wireless Access: In this case fixed connection is given to customer premise and the modem is provisioned to home. Then modem is activated and MAC \& IP is assigned to it (Example: NETGEAR modem) and then it acts as hotspot/wifi and radiates fixed length radio frequency (Microwave). It has limited coverage region. Lower frequency can traverse long distance and can better penetrate the wall.

\section{Common Wireless Standards (Speed in Megabits):}

* Wi-Fi 802.11a (up to 2Mbps) - Frequency: $2.4 \mathrm{GHz}$ or $5 \mathrm{GHz}$

*Wi-Fi 802.11 b (up to 11Mbps) - Frequency: $2.4 \mathrm{GHz}$

*Wi-Fi 802.11g (up to 54Mbps) - Frequency: $2.4 \mathrm{GHz}$

*Wi-Fi 802.11n (up to 600Mbps) - Frequency: 2.4GHz or $5 \mathrm{GHz}$

* Wi-Fi 802.11ac (up to 1700Mbps) - Frequency: $5 \mathrm{GHz}$

* Wi-Fi 802.11ac-2013 (up to 7000Mbps) - Frequency: $5 \mathrm{GHz}$

* Wi-Fi 802.11ad (up to 7000Mbps) - Frequency: $60 \mathrm{GHz}$ (short range)

* WiMAX 802.16/d (up to 1Gbps+) - Frequency: $2.3 \mathrm{GHz}$, $2.5 \mathrm{GHz}, 2.6 \mathrm{GHz}, 3.5 \mathrm{GHz}$

* 4G TD LTE (up to 1000Mbps+) - Frequency: $3.5 \mathrm{GHz}$, 3.6GHz 


\section{BB Power Line Transmission}

In this case, $\mathrm{BB}$ transmission can be conducted along with existing power cables that is going over head. It carries power and internet service on the same wire with different wavelength. It is much helpful in remote coverage area where ISPs don't have any exchange office or giving connection becomes too costly. But, it suffers from high levels of interference. In trial run, $200 \mathrm{Mbps}$ speed was achieved in UK. Example: TREFOR network (Power Company) of Denmark provides both internet and power.

\section{NEW TECHNOLOGIES}

Different new technologies are introduced to increase speed on existing lines to provide more speed and more customer support:

- Triple Play: It is a marketing term to provision BB internet access and Television (BW intensive service) and Telephone (Latency intensive) over a single BB connection plan.

Pair Bonding: Applicable to Alcatel DSLAMs on copper line. Instead of single pair of copper, it uses two to bridge the BW gap. It combines the payload of 2 or more DSL links into single fat pipe. It increases the data rate. It can deliver 50+ Mbps over Copper VDSL2 Bonding. To support PB, new PB supported VDSL/ADSL card needs to be installed at DSLAM end. Pair Bonding is also applicable on SHDSL.

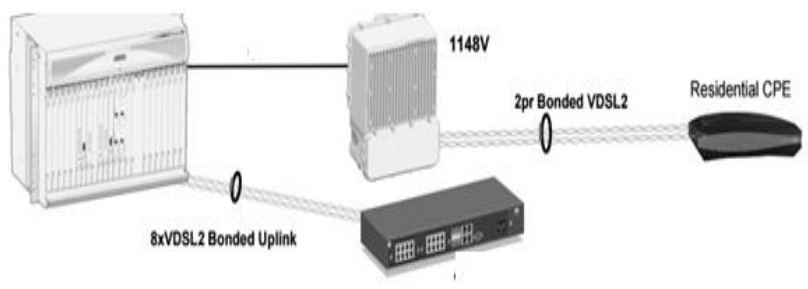

Fig: 11 Pair Bonding

- G.Fast: G.Fast with FTTB can bring fiber lines more closely to home and push speed up to $1 \mathrm{Gbps}$ via short end copper cable. It works similar to the $80 \mathrm{Mbps}$ FTTC but requires more frequencies $(106+\mathrm{Mhz})$ to support more speed to the end copper with local loop ideally less than 250 meters. G.Fast with PON network can provide significant improvements in terms of both cost and performance in the network.

- Vectoring: It is applicable to Alcatel DSLAMs on copper line. Its purpose is to increase the speed of existing VDSL2 (G.993.2/FTTC) and support more customer by reducing crosstalk and noise on copper. It can serve subscribers over a wide range of $1 \mathrm{Km}$ (length of local loop). VDSL 17a $(17 \mathrm{MHz})$ represents VDSL with Vectoring where VDSL 35a $(35 \mathrm{MHz})$ represents VDSL with V-Plus as per ITU. VDSL with Vectoring card must be installed on Alcatel DSLAM to have this feature. Vectoring is defined by the ITU-T standard G.993.5.

- G.INP: It is referred to as Impulse Noise Protection/ Physical Retransmission. It is defined by the ITU-T standard G.993.5. It is a new alternative to Forward Error correction method and rectifies only there is error in transmission. It operates at physical layer and transmitting modem keeps a copy of data in retransmission buffer. If receiver detects any error via checksum method, retransmission gets initiated \& the RTT must be less than $4 \mathrm{~ms}$. If retransmission does not happen then corrupted data sent to upper layer protocols to sort it out. Vectoring with G.INP on copper line makes the connection more powerful.

- Link Aggregation: It is basically a bonding concept on both copper \& Fiber line to provide end customer a better and enhanced speed by aggregating ports. A LAG or Link Aggregation Group combines multiple physical ports to provide a single data path with high $\mathrm{BW}$. In the group there can a load sharing feature to make connection more stable and reliable. It also provides redundancy if one of the links fail. LACP is defined in IEEE and aggregation can happen in physical Layer (combining multiple frequency bands), Data Link Layer (switching port aggregation), and Network Layer in OSI layer.

- Removing Switches: The concept is to connect DSLAMs directly with L3 and remove the overhead at L2 switches (BW problem, MAC problem, Capacity problem, VLAN allocation problem \& old switching problem). It is a slow migration task decided by capacity department of a telecom company. There can be two types of switches (which are basically based on ring topology and single failure can break entire connection down) - a) DSLAM to Customer b) L3 to DSLAM. These switches can be removed in a phase to provide more stable connections.

- V-Plus: It can provide better performance than both VDSL2 Vectoring and G.Fast. Actually, it closes the gap between VDSL2 and G.Fast. It can serve subscribers with high performance in the local loop length of 250 (up to $300 \mathrm{Mbps}$ )$550 \mathrm{~m}$ (Up to 200Mbps).

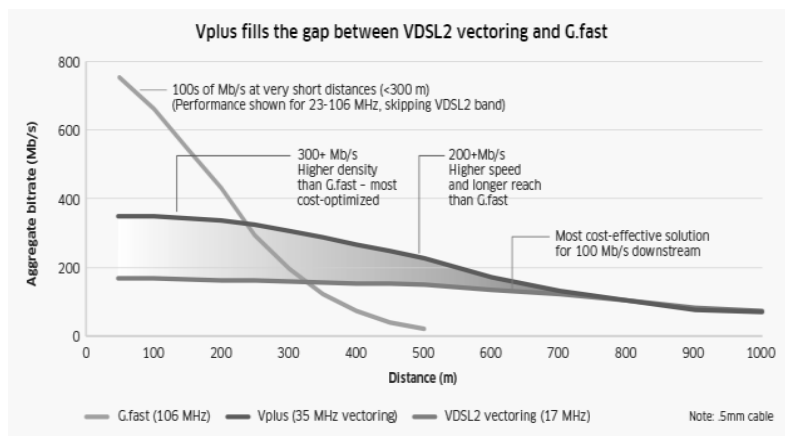

Fig: 12 Vplus Performance

This service has earned huge revenue on existing FTTC service. It has reduced subscription cost with increased people density and it supports easy up gradation from VDSL 17a to V-Plus. Both can exist on same local loop. Its frequency is $35 \mathrm{MHz}$ (VDSL has $17 \mathrm{MHz}$ ). To support this new VDSL card with this feature needs to be installed on Alcatel DSLAM.

- GIGA COAX \& DOCSIS 3.1: It is an approach taken by Denmark Yousee ISP. It is based on coax connection and all residential customers are given $\mathrm{BB}, \mathrm{TV}$, VoIP services on single coax line. Now, there is a demand to increase the speed of end users and coverage on larger distance with more customer support and good profit. The target is to amplify the signal at customer end with new 3.1 amplifiers (DOCSIS 3.1). for this, some modification has to be made like new 3.1 wall plug must be installed at customer premise \& OLT with 10GPON \& optical splitter will be introduced in the network (CO \& ON). The Solution must provide $1 \mathrm{~GB} / \mathrm{s}$ download and $500 \mathrm{Mb} / \mathrm{s}$ upload for all Broadband Customers. (Increase customer experience by launching $\geq \mathbf{1}$ Gbit/s download and $\geq 60 \mathrm{Mbit} / \mathrm{s}$ upload speeds by end of 2016 and $\geq \mathbf{5 0 0 M b i t} / \mathrm{s}$ 
upload speeds as soon as possible thereafter, ensure full network coverage nationally in Denmark for its HFC Network by end of 2017 (to meet the traffic growth of $42 \%$ CAGR)) and provides solution guarantee its maximum capacity in the Network.

\section{CONCLUSION}

Today we are able to communicate across the boarders and the space-time gap has reduced remarkably. We are now able to watch $\mathrm{TV}$, enjoy different VAS services like online newspaper, online book store etc, can use VoIP services on single BB plan and it helps us to communicate across the globe more direct and instant and in reduced cost. Now, BB speeds are also improved with the introduction of fiber technology and it helps to increase the speed from Kbps to Gbps. New technologies have also improved speed, reduced subscription cost on existing copper connection. A lot of experiments are going on VDSL card for further improvements.

\section{REFERENCES}

[1] AT \& T Bell Laboratories technical journal. Vols. 1-10, 1922-31. 1 v.; Vols. 11-20, 1932-41. 1 v.; Vols. 31-40, 1952-61. $1 \mathrm{v}$.

[2] IEEE Journal on Selected Areas in Communications. Volume 20 Issue 5, September 2006 Page 1064-1074.
[3] International Journal of Communication Networks and Information Security (IJCNIS). Vol. 1, No. 1, April 2009. Modeling of Environmental Influences at the Signal Transmission by means of VDSL and PLC Technologies.

[4] J.T. Aslanis, J.M. Cioffi. "Achievable information rates on digital subscriber loops: Limiting information rates with crosstalk noise", IEEE Transactions on Communications, Vol. 40, No. 2, pp. 361-372, 1992.

[5] Scientific and Technical Information Processing, 38 57. 10.3103/S0147688211020031.

[6] K.S. Jacobsen. "Interactions Between ADSL and VDSL in the Same Binder: Simulations and Test Results." ANSI T1E1.4 contribution number 99-298. Ottawa, Ontario. June 1999.

[7] VDSL Alliance, T. Pollet, ed. "Physical Medium Specific Specification for G.vdsl." ITU SG15 contribution number MA-050. March 1999

[8] T. Starr, J.M. Cioffi, and P.J. Silverman. Understanding Digital Subscriber Line Technology. Prentice-Hall, Upper Saddle River, NJ, 1999.

[9] J.M. Cioffi, et. al. "Very-High-Speed Digital Subscriber Lines.” IEEE Communications Magazine, vol. 37, no. 4, April 1999, pp. $72-79$ 